\title{
Precipitation variability assessment of northeast China: Songhua River basin
}

\author{
Muhammad Imran Khan ${ }^{1}$, Dong Liv ${ }^{1, *}$, Qiang Fu ${ }^{1}$, Muhammad Azmat ${ }^{2,3}$, Mingue Luo ${ }^{1}$, \\ YuXiang Hu${ }^{1}$, Yonguia Zhang ${ }^{1}$ and FAIZ M ABRAR ${ }^{1}$ \\ ${ }^{1}$ School of Water Conservancy \& Civil Engineering, Northeast Agricultural University, Harbin Heilongjiang \\ 150030, China; Key Laboratory of Water-Saving Agriculture of Universities in Heilongjiang Province, \\ Northeast Agricultural University, Harbin Heilongjiang 150030, China \\ and \\ Key Laboratory of High Efficient Utilization of Agricultural Water Resource of Ministry of Agriculture, \\ Northeast Agricultural University, Harbin Heilongjiang 150030, China. \\ ${ }^{2}$ Department of Environment, Land and Infrastructure Engineering (DIATI), Politecnico Di Torino, 10129 \\ Torino, Italy. \\ ${ }^{3}$ Institute of Geographical Information Systems (IGIS), School of Civil and Environmental Engineering (SCEE), \\ National University of Sciences and Technology (NUST), H-12, Islamabad, Pakistan. \\ *Corresponding author.e-mail: liudong5511@sina.com
}

Variability in precipitation is critical for the management of water resources. In this study, the research entropy base concept was applied to investigate spatial and temporal variability of the precipitation during 1964-2013 in the Songhua River basin of Heilongjiang Province in China. Sample entropy was applied on precipitation data on a monthly, seasonally, annually, decade scale and the number of rainy days for each selected station. Intensity entropy and apportionment entropy were used to calculate the variability over individual year and decade, respectively. Subsequently, Spearman's Rho and MannKendall tests were applied to observe for trends in the precipitation time series. The statistics of sample disorder index showed that the precipitation during February (mean 1.09, max. 1.26 and min. 0.80), April (mean 1.12, max. 1.29 and min. 0.99) and July (mean 1.10, max. 1.20 and min. 0.98) contributed significantly higher than those of other months. Overall, the contribution of the winter season was considerably high with a standard deviation of 0.10 . The precipitation variability on decade basis was observed to increase from decade 1964-1973 and 1994-2003 with a mean value of decadal apportionment disorder index 0.023 and 0.053, respectively. In addition, the Mann-Kendall test value (1.90) showed a significant positive trend only at the Shangzhi station.

\section{Introduction}

Changes in the global water cycle are not uniform in the $21^{\text {st }}$ century and precipitation is a major factor that plays a key role in the cycle of water resources and provides information on changes in climate (IPCC 2013). Precipitation durations, timing, rate and intensity are largely influential in climatic variations which further affect the management of water resources (Azmat et al. 2015). As a result, such irregularities in precipitation, i.e., droughts and floods can affect the ecological system adversely (Zhang et al. 2013). Recently, the eco-hydrological system has been affected

Keywords. Entropy; spatial-trends; temporal-trends; disorder index. 
by these irregular precipitation events (Beniston and Stephenson 2004). Trends and changes in climatological variables such as temperature and precipitation are very important for water management particularly to fulfil the future challenges due to global warming and rapid growth in population (Cannarozzo et al. 2006; Oguntunde et al. 2006). Investigations of rainfall trends are necessary to understand the significance of changes in climate for the development and management of water resources (Haigh 2004).

The unexpected variations in the rainfall patterns are the key problems for the development of water resources and its use (Azmat et al. 2016). While formulating present or future regional nationwide water requirement strategy, the property of disorder over the region can be the most influencing factor in making the decision of development. Entropy is one of the techniques developed by Shannon (1948) which further comprises of different analytical approaches to measure the complexity of precipitation behaviours such as information entropy, wavelet entropy, apportionment entropy and intensity entropy. Singh (1997) analysed the informational entropy theory applications on the problems of hydrological and water resources development. Mostly, the application of entropy is in the perspective of the probability of occurrence, for example, intensity entropy can measure the variability of hydrological variables. Singh and Fiorentino (1992) applied the entropy concept for the investigation of relationships among drought, rainfall and flood monitoring stations due to their greater dependence on each other. Moreover, several non-parametric tests (Mann-Kendall and Spearman Rho) are widely used to identify the trends in metrological time series. Several researchers have investigated the precipitation trends in northeast China (e.g., Liang et al. 2011). Liu et al. (2014) conducted a trend analysis to examine the extreme precipitation and noticed a rise in extreme precipitation events in China. Recently, $\mathrm{Li}$ et al. (2014) investigated spatial and temporal fluctuations in annual precipitation using a 50-year dataset from 1960 to 2009 by applying the MannKendall test and observed that there is a considerable declining trend in precipitation. Zhang et al. (2011) used the Mann-Kendall test to examine variation in monthly precipitation during 19602000 (40 years) on a spatial and temporal basis, and the results revealed the presence of declining trends at about $45 \%$ stations annually in northeastern China. Azmat (2015) analysed the correlation between climate variables (precipitation, temperature and stream flow) using Mann-Kendal and Pearson correlation tests during 1961-2009, in northern Pakistan. The aforementioned studies presented an overview of monthly and annual precipitation trends of different river basins worldwide, using regression techniques or nonparametric tests without considering entropy theories, which provide a detailed spatial and temporal pattern of precipitation; however, this study is an attempt to investigate the variability of precipitation pattern spatially and temporally within seasons (winter, summer, spring and fall), months (January-December), years and decades. The specific objectives of this study were to investigate the precipitation variability on different timescales, i.e., monthly, seasonally, decadal and annual using the entropy base concept. Subsequently, the Disorder Index (DI) was utilised on the resulting data generated using sample entropy theory to investigate the distribution of precipitation on spatial as well as temporal scale in Songhua River basin. DI is used to measure precipitation variability and it is the difference between the maximum possible values under evenly apportioned state to the value acquired from the actual entropy time series. The high value of DI indicated a high variability. Further, non-parametric tests (Mann-Kendall and Spearman Rho) were utilised to investigate the trends of precipitation in the study area.

For this purpose, different entropy theories and statistical techniques were applied to analyse the trends of precipitation for the identification of changes in climate due to variations in precipitation.

\section{Study area and datasets}

Harbin is the provincial capital of the Heilongjiang province of China which is located in $44^{\circ} 04^{\prime}-$ $46^{\circ} 40^{\prime} \mathrm{N}$ and $125^{\circ} 42^{\prime}-130^{\circ} 10^{\prime} \mathrm{E}$. The Heilongjiang province has a mild and humid climate with a mean annual precipitation of $500-600 \mathrm{~mm}$ (Guo et al. 2009); however, high variability of precipitation exists due to non-uniformity of precipitation in the study area. The climate is temperate zone continental monsoon with long winters and short summers. We used entropy theories to estimate the high variability in precipitation time series. The uneven and complex distribution of annual precipitation makes the hydrological behaviour of the study area more peculiar. Study of the complexity of water resources system is necessary for the optimal allocation of regional water resources. Therefore, it is important to examine the complexity of precipitation in order to develop a trend analysis and efficient use of water resources.

Daily precipitation data of 11 meteorological stations were acquired out from Meteorological Administration of Heilongjiang Province for the period 1964-2013 (50 years). Moreover, the area 


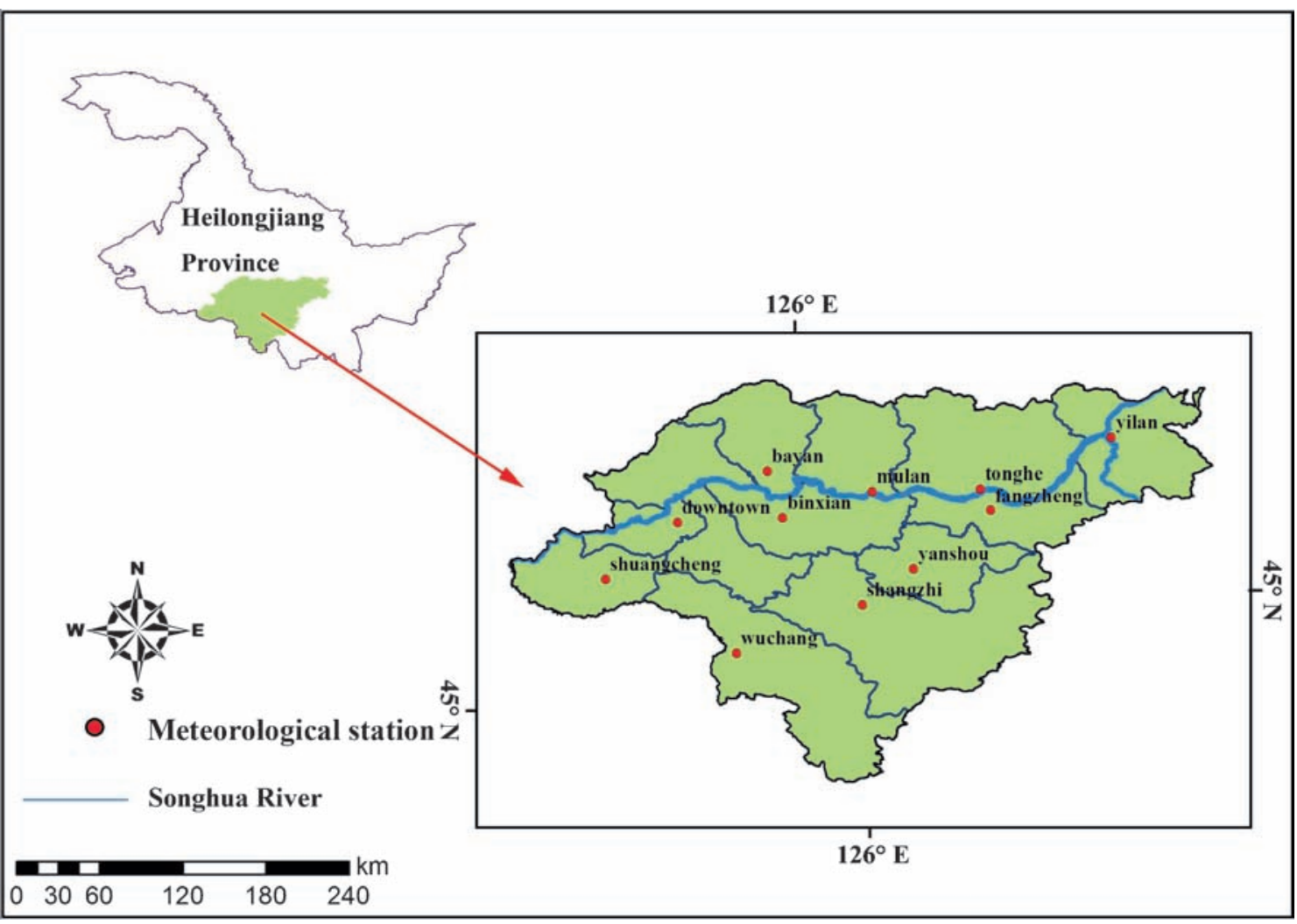

Figure 1. Map of the precipitation stations.

Table 1. Code of stations with mean precipitation.

\begin{tabular}{|c|c|c|c|c|c|c|c|}
\hline \multirow[b]{2}{*}{ Station no. } & \multirow[b]{2}{*}{ Name } & \multirow[b]{2}{*}{$\begin{array}{c}\text { Station } \\
\text { ID }\end{array}$} & \multicolumn{5}{|c|}{ Precipitation $(\mathrm{mm})$} \\
\hline & & & Winter & Spring & Summer & Fall & $\begin{array}{c}\text { Mean } \\
\text { annual }\end{array}$ \\
\hline 1 & Downtown & 50953 & 259 & 743 & 3431 & 806 & 436 \\
\hline 2 & Bayan & 50867 & 200 & 797 & 3919 & 830 & 479 \\
\hline 3 & Yilan & 50877 & 263 & 876 & 3501 & 890 & 460 \\
\hline 4 & Shuangcheng & 50955 & 201 & 677 & 3328 & 693 & 408 \\
\hline 5 & Binxian & 50960 & 268 & 858 & 3657 & 883 & 472 \\
\hline 6 & Mulan & 50962 & 277 & 887 & 3879 & 915 & 496 \\
\hline 7 & Tonghe & 50963 & 289 & 908 & 3629 & 891 & 476 \\
\hline 8 & Fangzheng & 50964 & 322 & 936 & 3570 & 965 & 482 \\
\hline 9 & Yanshou & 50965 & 264 & 900 & 3711 & 906 & 481 \\
\hline 10 & Shangzhi & 50968 & 417 & 998 & 4037 & 974 & 535 \\
\hline 11 & Wuchang & 54080 & 327 & 912 & 3880 & 843 & 496 \\
\hline
\end{tabular}

is divided into four blocks; southeast, southwest, northeast and northwest. The location and the respective codes of the stations along with precipitation are presented in figure 1 and table 1 .

\section{Material and methods}

Precipitation variability can be measured using entropy on the temporal and spatial scale. Precipitation data of monthly, seasonal, and annual time series were used to estimate the variability within a year, season and month. The climatic system uncertainty (variability, disorder) includes the variability of quasi-periodic (Mann and Park 1999) which have been directly linked to decadal and multi-decadal periods of precipitation anomalies. Therefore, it is important to measure the uncertainty (disorder, variability) on the temporal (decade, season, month-wise) and spatial (by comparing individual precipitation station with overall stations) scales. For this purpose, different types of entropy theories were used to analyse the precipitation data. 


\subsection{Entropy}

Entropy is a measure of unevenness of probability distribution which provides us with the level of deviation in a data sample. Since the low unevenness attained from large dataset provides reliable information about input data. The idea of entropy developed by Shannon (1948) is a measure of unevenness, dispersion and disorder. An equation of entropy $H(x)$ given by Shannon (1948) is

$$
H(x)=-\sum_{k=1}^{k} p\left(x_{k}\right) \log \left[p\left(x_{k}\right)\right]
$$

where $K=$ discrete data interval and $p\left(x_{k}\right)=$ probability of $x_{k}$.

$p\left(x_{k}\right)$ probability depends upon the value of $x$ and variable $x$ has $k$ outcomes. It is essential to choose the value of the finite interval $k$ for unravel variables. Entropy $H(x)$ indicates the uncertainty of outcome in a process. The value of $H$ changes from zero to $\log 2 k$. If $H=0$, it means that the probability of a particular state is 1 . If this condition exists, it means that we are able to know the complete information of that particular state in the process. The value of entropy increases/decreases with increase/decrease in the number of constraints (Kawachi et al. 2001).

\subsubsection{Sample entropy}

Sample entropy $(m, n$ and $r)$ is the negative algorithm of conditional probability for ' $m$ ' connective terms within the tolerance of ' $r$ ' with length ' $n$ ' time series. Sample entropy is represented by SE. The value of sample entropy is measured using the equation (Richman and Moorman 2000):

$$
\mathrm{SE}=-\ln \left(\sum_{i=1}^{N-M} n_{i}^{m+1} / \sum_{i=1}^{N-M} n_{i}^{m}\right)
$$

where $n_{i}^{m}$ and $n_{i}^{m+1}$ show the numbers in time series of tolerance criteria (matching criterion) $r$ with length of $m+1$ and $m$. The tolerance criteria $r$ (0.1-0.2) and length $m$ depend on the length of time series (Lake et al. 2002).

\subsubsection{Intensity entropy}

Intensity entropy (IE) is the ratio of the number of rainy days in a month to the total number of rainy days in a year. Many researchers have used intensity entropy such as (Singh 1997; Maruyama and Kawachi 1998). The intensity entropy can be defined as follows:

$$
\mathrm{IE}=-\sum_{i=1}^{m}\left(\frac{n_{i}}{N}\right) \log _{2}\left(\frac{n_{i}}{N}\right)
$$

where $n_{i} / N=$ frequency $\left(p_{i}\right) ; n_{i}=$ number of rainy days in a month of a year; $N=$ total number of rainy days in a year; and $m=$ class interval.

\subsubsection{Apportionment entropy}

Apportionment entropy (AE) measures the variability of precipitation on a temporal scale. If $r_{i}$ is the total precipitation in a month, then total precipitation $(R)$ in a year can be expressed as:

$$
R=\sum_{i=1}^{12} r_{i}
$$

Finally,

$$
\mathrm{AE}=-\sum_{i=1}^{12}\left(\frac{r_{i}}{R}\right) \log _{2}\left(\frac{r_{i}}{R}\right)=-\sum_{i=1}^{12}\left(p_{i} \log _{2} p_{i}\right)
$$

where $p_{i}=$ probability of occurrence.

\subsubsection{Decadal apportionment entropy}

This entropy is used to measure the randomness of data on a decade basis. For example, the apportionment entropy of a decade can be expressed as:

$$
D R=\sum_{i=10}^{10} a_{i}
$$

where $a_{i}=$ precipitation during $i$ th year.

$d_{i}=a_{i} / D R=$ occurrence probability of the outcome. The final equation can be written as:

$$
\mathrm{DAE}=\sum_{i=1}^{10} d_{i} \log _{2} d_{i}
$$

$$
\mathrm{DAE}=\sum_{i=1}^{10}\left(\frac{a_{i}}{D R}\right) \log _{2}\left(\frac{a_{i}}{D R}\right) .
$$

Disorder index is used to measure the precipitation variability and can be defined as the difference between the maximum possible values evenly allocated to the value acquired from the actual entropy time series. If disorder index is used for the calculation of sample entropy, it is called sample disorder index (SDI). Similarly, it is called apportionment disorder index (ADI) when it is used for the calculation of apportionment entropy. When the analysis on decade basis is carried out using decadal apportionment entropy, it is called decadal apportionment disorder index (DADI).

\subsection{Trend analysis}

Many statistical techniques are used to detect the trends within time series such as Mann-Kendall 
test, Spearman's Rho test, Sen's slope estimator and linear regression. In this study, Mann-Kendall and Spearman's Rho tests were applied to detect the trends in precipitation data during the period 1964-2013.

\subsubsection{Mann-Kendall trend test}

The Mann-Kendall test statistic $(S)$ given by (Mann 1945; Kendall 1975) is calculated using the formula given as:

$$
S=\sum_{i=1}^{n-1} \sum_{j=i+1}^{n} \operatorname{sgn}\left(x_{j}-x_{i}\right)
$$

where $x_{i}$ and $x_{j}=$ values of $i$ and $j(j>i)$ in time series, $\operatorname{sgn}\left(x_{j}-x_{i}\right)$ is the sign function, $N=$ number of data points, and

$$
\operatorname{sgn}\left(x_{j}-x_{i}\right)= \begin{cases}+1 & \text { if } x_{j}-x_{i}>0 \\ 0, & \text { if } x_{j}-x_{i}=0 \\ -1 & \text { if } x_{j}-x_{i}<0\end{cases}
$$

If sample size $n>10$, the mean and variance are given by $\mu(s)=0$

$\sigma^{2}(s)=n(n-1)(2 n+5)-\frac{\sum_{i=1}^{m} t_{i}\left(t_{i}-1\right)\left(2 t_{i}+5\right)}{18}$

where $t_{i}=$ number of ties of extent $i$ and $m=$ number of tied group.

A set of data containing the same values is called tied group. If tie values are absent between the observations then

$$
\sigma^{2}(s)=\frac{n(n-1)(2 n+5)}{18} .
$$

The standard normal test statistic $Z_{S}$ is computed as:

$$
Z_{S}= \begin{cases}\frac{s-1}{\sqrt{\sigma^{2}(s)}}, & \text { if } s>0 \\ 0, & \text { if } s=0 \\ \frac{s+1}{\sqrt{\sigma^{2}(s)}}, & \text { if } s<0\end{cases}
$$

Positive and negative values of $Z_{S}$ represent the increasing and decreasing trends, respectively. The trend analysis was carried out at a 5\% significance level and at this level, the null hypothesis of no trend was rejected, if $\left|Z_{S}\right|>1.96$.

\subsubsection{Spearman's Rho test}

Spearman's Rho is a non-parametric test used to measure the absence of trend. Its statistic $D$ and the standardized test statistic $Z_{D}$ are expressed as follows (Lehmann 1975; Sneyers 1990):

$$
D=1-\frac{6 \sum_{i=1}^{n}\left(R\left(x_{i}\right)-i\right)^{2}}{n\left(n^{2}-1\right)}
$$

$$
Z_{D}=D \sqrt{\frac{n-2}{1-D^{2}}}
$$

where $n=$ length of time series and $R\left(x_{i}\right)=$ rank of $i$ th observation in time series.

The positive values of $Z_{D}$ show increasing trends and the negative values of $Z_{D}$ show decreasing trends. The null hypothesis of no trend is rejected if $\left|Z_{D}\right|>2.08$ at $5 \%$ significance level.

\section{Results and discussion}

\subsection{Variability of precipitation (annual, seasonal and monthly basis)}

Sample disorder index was used to calculate the monthly, seasonal and annual precipitation variability. Disorder index is the difference between maximum possible entropy values under evenly apportioned state to the value of actual entropy from time series, as discussed in section 3.1.4. Daily precipitation data was used to measure the SDI in terms of monthly and seasonal time series.

\subsubsection{Monthly precipitation variability}

The obtained statistical results of the SDI of different seasons on a monthly basis are given in table 2 . The results presented in table 2 were obtained for each individual month and for whole seasons such as spring, summer, fall and winter. The statistical descriptors were obtained on a spatial and temporal basis. Comparison analysis of precipitation for different seasons (winter, spring, summer and fall) and months within the seasons at each station are presented in figure 2. The minimum, maximum, mean and standard deviation SDI values varied from $0.72-0.92,1.08-1.25,1.0-1.09$ and $0.049-0.15$, respectively, during the winter season (NovemberFebruary). Similarly, for the spring season (MarchMay) the minimum, maximum, mean and standard deviation ranges were $0.88-0.99,1.14-1.29$, $1.06-1.11$ and $0.084-0.093$, respectively.

Table 2 depicts that the variability of precipitation is dominant during the month of February with mean and maximum values 1.09 and 1.26, respectively, in the winter season at most of the stations. It was noticed that variability in the winter season was less (mean value of SDI 0.98) when compared to the individual months (November, December, January, and February) which ranges from 1.0 to 1.09 . In spring, the variability was relatively less at most of the stations in the month of April as compared to the other two months of the spring season - March and May. The precipitation contribution of the month of April seems superior compared to other spring months with a mean SDI 

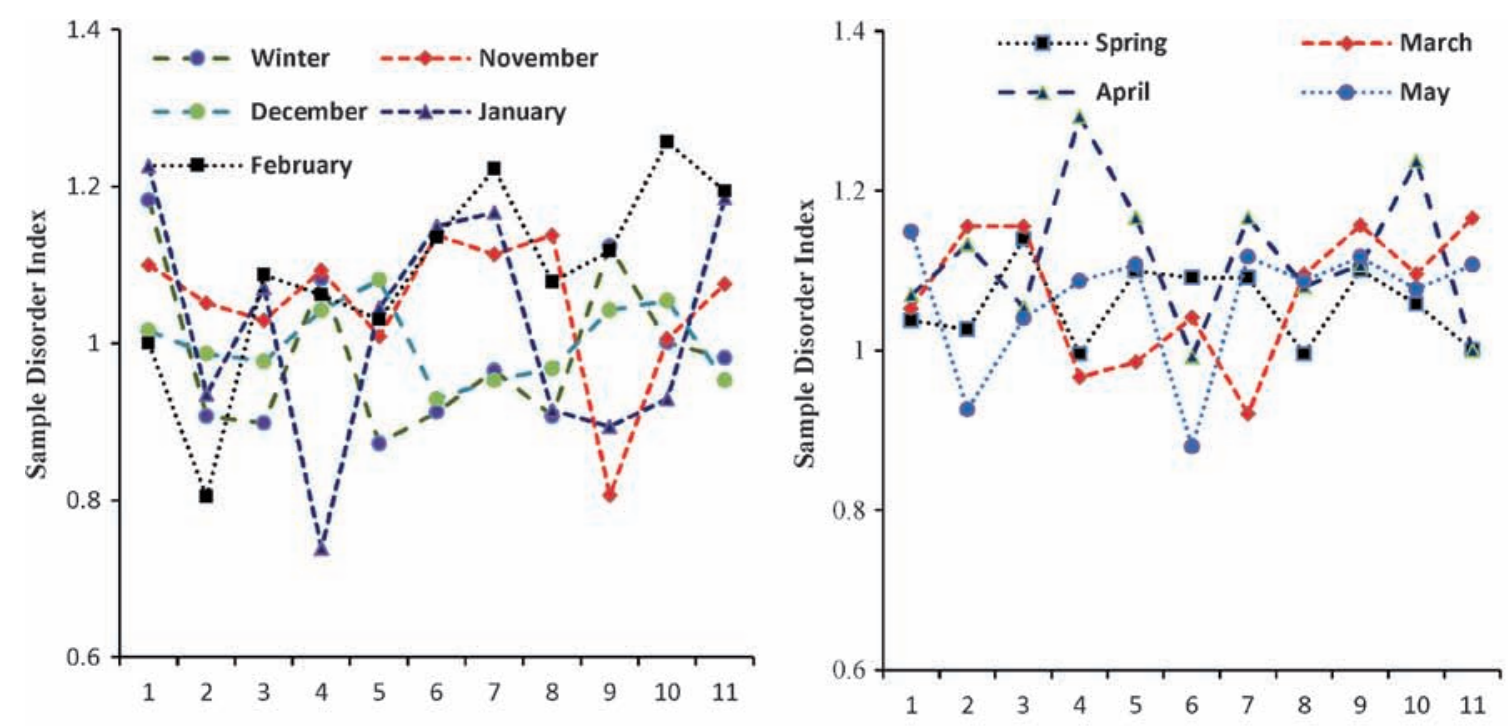

(a)

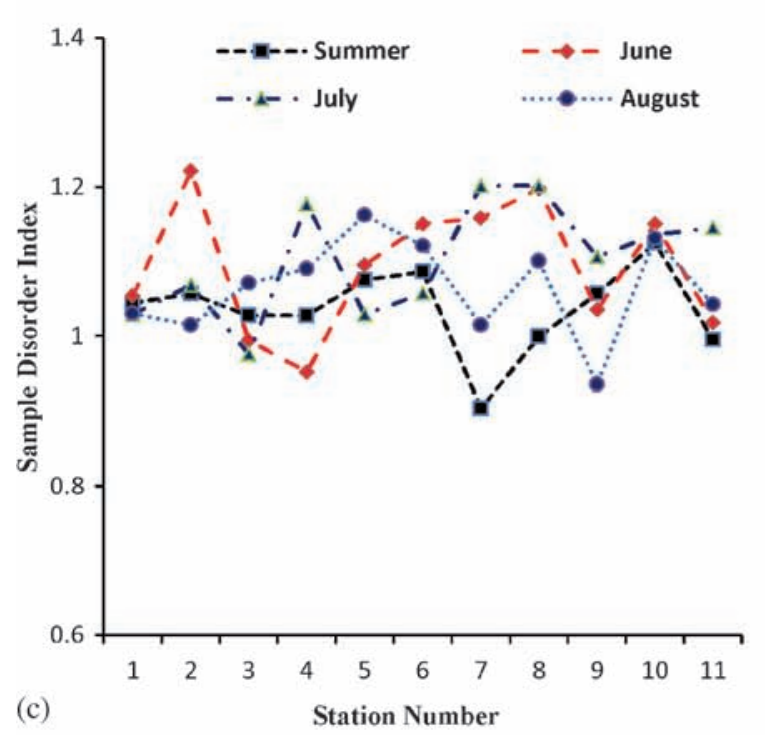

(b)

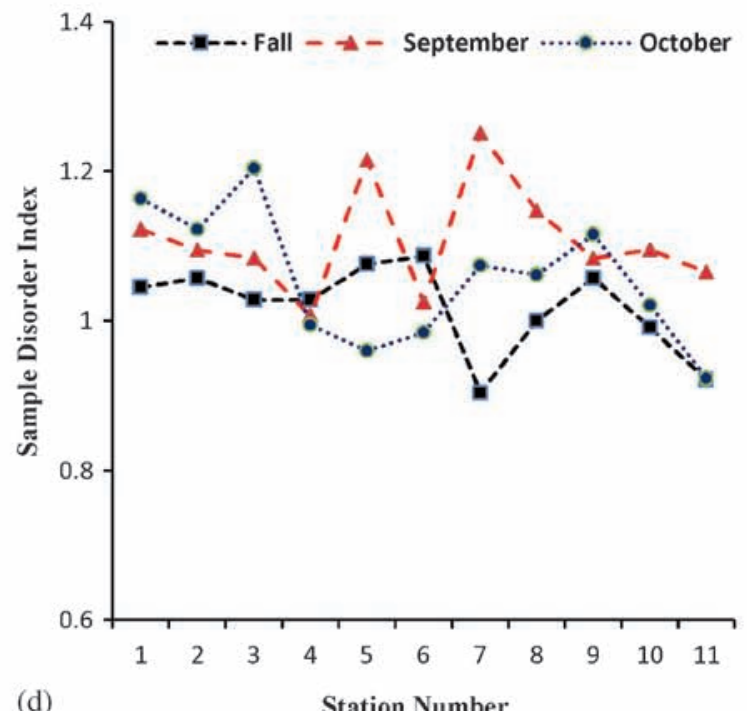

(d)

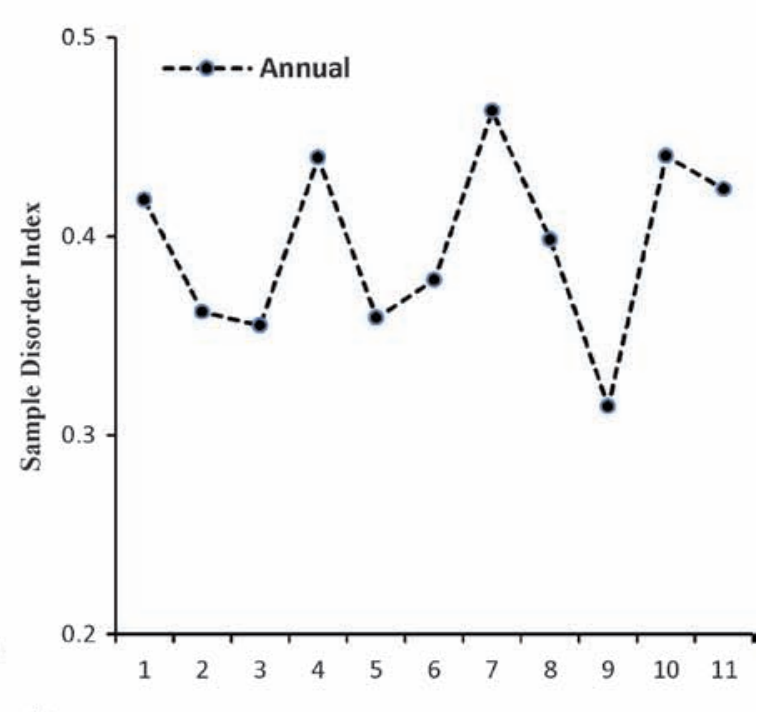

(f)

Station Number

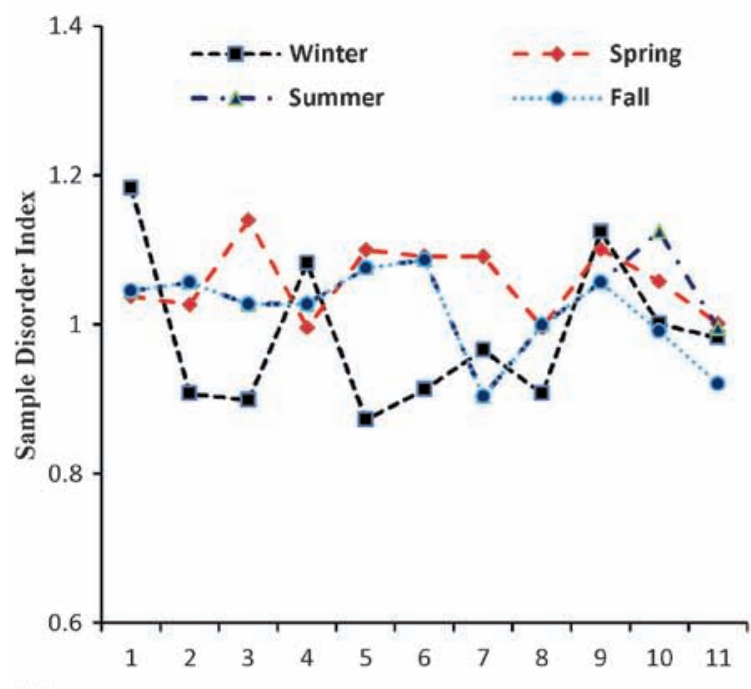

(e)

Station Number

Figure 2. Sample disorder index (SDI) for different precipitation time series. (a) Winter season, (b) Spring season, (c) Summer season, (d) Fall season, (e) different season precipitation, and (f) annual precipitation. 
Table 2. Statistical values of sample disorder index (SDI) for seasonal data series along with relevant months.

\begin{tabular}{llllll}
\hline Season & Month & Min & Max & Mean & Std. dev. \\
\hline Winter & November & 0.8068 & 1.1382 & 1.051218 & 0.093739 \\
& December & 0.9292 & 1.0814 & 1.000509 & 0.049573 \\
& January & 0.7392 & 1.2267 & 1.023536 & 0.15262 \\
& February & 0.8049 & 1.2572 & 1.090145 & 0.123745 \\
Spring & Winter & $\mathbf{0 . 8 7 2 8}$ & $\mathbf{1 . 1 8 3}$ & $\mathbf{0 . 9 8 5 3 3 6}$ & $\mathbf{0 . 1 0 2 8 7}$ \\
& March & 0.9212 & 1.166 & 1.072227 & 0.085778 \\
& April & 0.9926 & 1.2935 & 1.118318 & 0.093571 \\
\multirow{5}{*}{ Summer } & May & 0.8803 & 1.1488 & 1.063518 & 0.084443 \\
& Spring & $\mathbf{0 . 9 9 6}$ & $\mathbf{1 . 1 4 0 2}$ & $\mathbf{1 . 0 3 6 3}$ & $\mathbf{0 . 0 4 9 9 3 5}$ \\
& June & 0.9519 & 1.2212 & 1.093482 & 0.088596 \\
& July & 0.976 & 1.2014 & 1.102464 & 0.076127 \\
Fall & August & 0.9358 & 1.1621 & 1.064955 & 0.06505 \\
& Summer & $\mathbf{0 . 9 0 3 8}$ & $\mathbf{1 . 1 2 4 8}$ & $\mathbf{1 . 0 3 6 3}$ & $\mathbf{0 . 0 5 7 9 3 9}$ \\
& September & 1.0068 & 1.2511 & 1.108173 & 0.073729 \\
& October & 0.923 & 1.2043 & 1.056636 & 0.088956 \\
& Fall & $\mathbf{0 . 9 0 3 8}$ & $\mathbf{1 . 0 8 6 6}$ & $\mathbf{1 . 0 1 7 4}$ & $\mathbf{0 . 0 5 9 5 4 5}$ \\
\hline
\end{tabular}

of 1.12 and standard deviation of 0.09. Similarly, during the summer season, the precipitation contribution of the month of July was observed to be higher than that of all other months on the basis of mean, minimum and maximum values of SDI which were evaluated to be $1.10,0.97$, and 1.2 , respectively. These results are in agreement with the results obtained by Yang et al. (2010), who stated that the maximum precipitation occurred during the month of July (considered as flood period) in northeast China. The precipitation variability during the complete fall season was slightly less at most of the stations as compared to individual monthly analysis of September and October. The minimum, maximum, mean and standard deviation values of the complete fall season were found to be $0.90,1.08,1.017$ and 0.05 , respectively as compared to September and October with minimum (1.0, 0.92), maximum $(1.25,1.20)$, mean (1.1, $1.05)$ and standard deviation $(0.074,0.089)$ SDI value. Figure $2(\mathrm{a}-\mathrm{d})$ showed spatial precipitation variation in the form of Sample Disorder Index (SDI) value over individual monthly basis and during a complete season. The maximum variability of precipitation was found at Shangzhi station (10) during February while comparing monthly SDI values of the winter season with that of individual months (November, December, January) as shown in figure 2(a). Similarly, for spring season, a high variability was observed in Shuangcheng station (4) during April as shown in figure 2(b). The maximum SDI value at Bayan station (2) was recorded during the month of June (summer season) as compared to other summer months (July, August) as in figure 2(c). Similarly, the maximum value of monthly SDI was found at Binxian (5) and Tonghe station (7) during the fall season as shown in figure $2(\mathrm{~d})$.

\subsubsection{Seasonal precipitation variability}

The results for the seasonal precipitation variability obtained during 1964-2013 (50 years) at 11 different stations of Songhua River basin are presented in table 2. A higher precipitation variability during winter season was observed with a standard deviation value of SDI 0.103 as compared to spring, summer and fall with standard deviation values of SDI 0.049, 0.057 and 0.059, respectively. The lowest variability was found during the fall season with a mean value of 1.017 and standard deviation of 0.05 (table 2). The highest and lowest precipitation contribution occurred during the winter and fall seasons respectively, in the 50 years' time series during 1964-2013. Figure 2(e) shows the spatial precipitation variations at different stations on a seasonal basis. It is clear that the highest precipitation variability was observed at the Downtown station (1) during the winter season, while during spring, Yilan station (3) experienced the highest precipitation variability. Moreover, during the summer season no significant change in precipitation was observed at most of the stations except at Tonghe station (7) which showed a similar summer precipitation behaviour over the entire study basin. Figure 2(e) depicts the spatial variations (over different stations of Songhua River basin) of precipitation in the form of SDI on a seasonal basis (spring, summer, winter and fall). A large variability in precipitation was observed during the winter season as compared to other seasons. On the other hand, the 
variability during summer and fall were found very close to each other at most of the stations except for station number (10) and (11). Moreover, a minimum variation in precipitation was observed over the Songhua River basin during the spring season because of less difference between highest and lowest SDI values. The results show that the Songhua River basin is more influenced by the westerlies circulations (winter precipitation pattern) than the monsoon precipitation pattern.

\subsubsection{Annual precipitation variability}

Figure 2(f) shows the spatial and temporal precipitation variability on an annual basis. It can be seen that the precipitation variability on an annual basis is much less than that on a monthly and seasonal basis. A decreasing pattern of precipitation variability has been observed from north to south of Songhua River basin. The highest and lowest precipitation variability was observed at Tonghe (7) and Yanshou station (9) with SDI values of 0.46 and 0.31 , respectively (figure $2 \mathrm{f}$ ).

\subsection{Precipitation variability on spatial and temporal scale}

\subsubsection{Precipitation variability on temporal scale}

The apportionment disorder index (ADI) was used to measure variability in precipitation of different months within a year. ADI was used to calculate the temporal variability of monthly precipitation over a year. To measure the variability on a temporal scale, mean ADI is plotted with a threshold value in figure $3(\mathrm{a})$. The threshold value is the mean of historical ADI and is also called the longterm mean. The threshold value is used to differentiate between the lower and higher values. The precipitation values below the long-term mean value show that the variability in precipitation is low and the precipitation values above the long-term mean show a higher variability in precipitation. Figure 3(a) showed that a high variability in precipitation was found during the early 1970's, mid-1980's and late 1990's with ADI values in the range 0.80$0.99,0.85-1.06$ and $0.74-1.06$, respectively. On the other hand, variability was found low during 1976, 1977, 1980, and 2007 with ADI values 0.49, 0.78, 0.64 and 0.54 , respectively. This fact may be associated with the occurrence of uneven precipitation events during the aforementioned years.

\subsubsection{Precipitation variability on spatial scale}

In order to investigate the spatial precipitation variability over the Songhua River basin, the
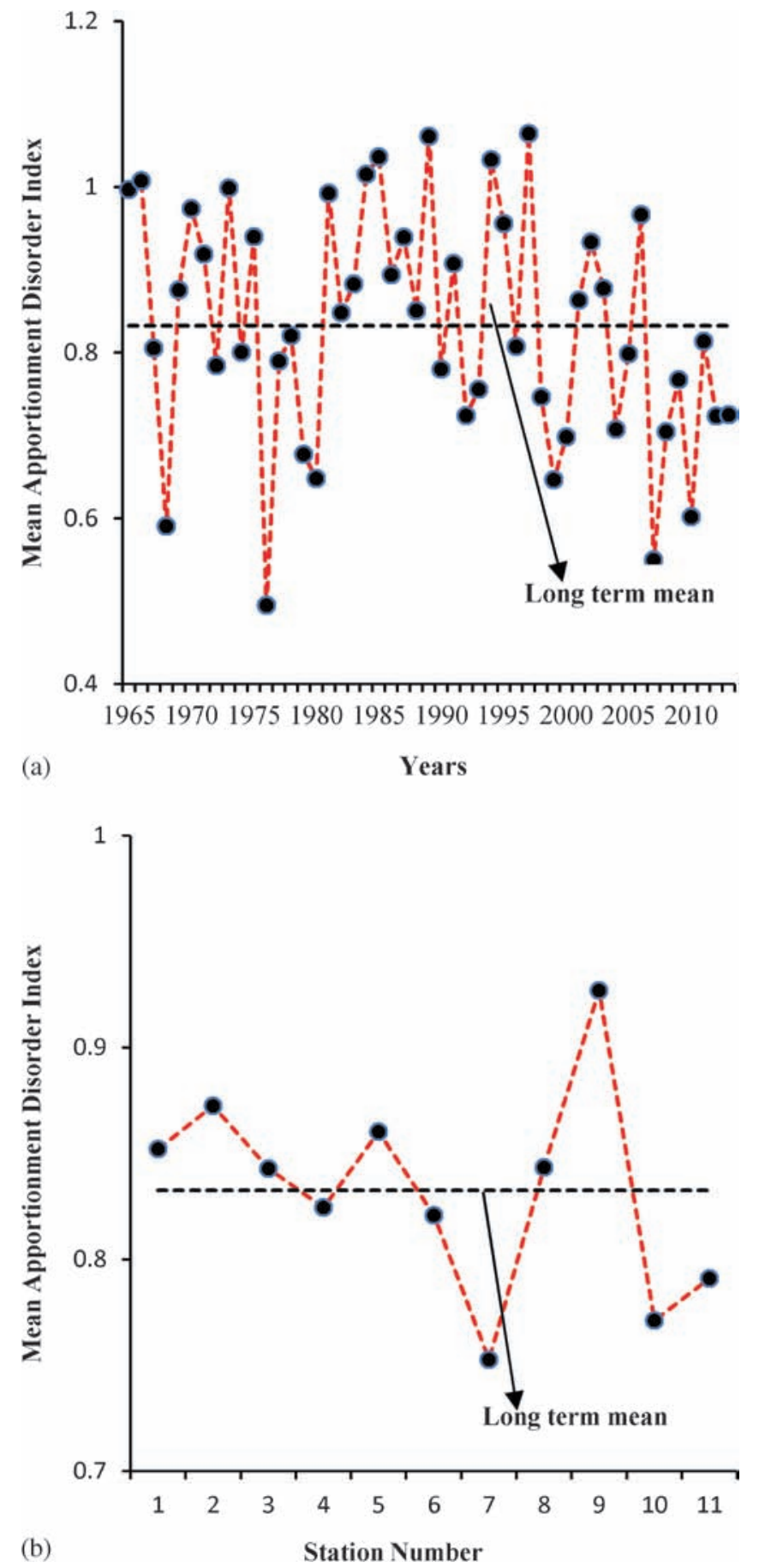

Figure 3. (a) Mean apportionment disorder index of different years over various precipitation stations. (b) Stationwise precipitation mean apportionment disorder index.

mean value of ADI of various stations is presented in figure 3(b). Additionally, a spatial precipitation distribution map is presented in figure 4 . The threshold value of ADI which is also called long term mean is used to differentiate between the high and low values. High precipitation variability was observed with ADI values of $0.85,0.87$ and 0.86 at Downtown (1), Bayan (2) and Binxian (5) 


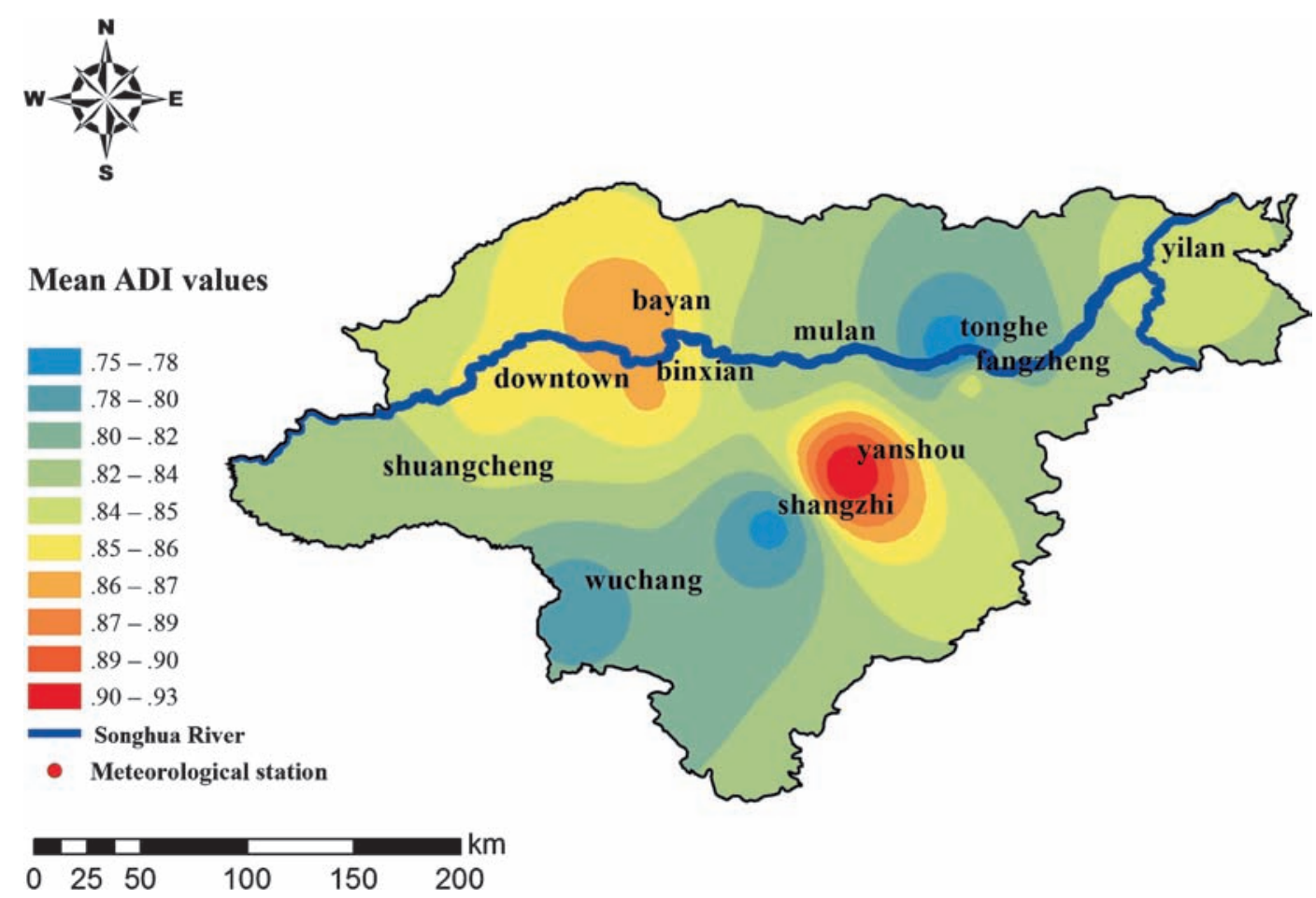

Figure 4. Spatial variability of the precipitation over the study area.

stations, respectively, while low precipitation variability was observed at Shangzhi (10) and Wuchang (11) stations, with mean ADI of 0.77 and 0.79 , respectively. An interesting rainfall pattern was noticed while plotting a spatial distribution of ADI values over the study basin. Generally, a pattern of decreasing variability, from the northern towards the southern part of the study area, was observed; however, the Tonghe and Yanshou stations showed an entirely contrary precipitation pattern. The Yanshou station showed a higher precipitation variability with mean ADI of 0.92 whereas the Tonghe station (7) showed a lower precipitation variability with a mean ADI of 0.75 . This fact may be associated with an uneven pattern of precipitation because at the same time several stations located in northern part of the Songhua River basin received higher precipitation in comparison with stations located in the southern part.

\subsection{Rainy days variability}

The intensity entropy concept was utilised to calculate the spatial and temporal rainy days variability. Intensity entropy was calculated for each year and at every station located within the Songhua River basin. The mean and threshold intensity entropy values were plotted together as presented in figure 5(a). Higher values of intensity entropy was found during 1968 (3.48), 1976 (3.49), 1978 (3.34) and 2000 (3.50), indicating a higher variability in the number of rainy days in accordance with $\mathrm{Fu}$ et al. (2013) who stated that the years 1968 and 1978 showed higher variability in the Songhua River basin. Overall, a consistent trend in the number of rainy days was found on a temporal basis from 1965 to 2013. Similarly, mean intensity entropy was calculated at different stations to investigate the variability of rainy days as shown in figure 5(b). High variability in precipitation was observed at Yilan (3), Mulan (6), Tonghe (7), Shangzhi (10) and Wuchang (11) stations with mean intensity entropy values of $3.41,3.43,3.43,3.44$ and 3.42 , respectively. The aforementioned stations are located at the southeast part of the study basin; therefore, it can be concluded that the precipitation variability pattern increases from the southeast to the northwest part of the Songhua River basin. This may be associated with the fact that there is an occurrence of less precipitation at southeast as compared to the northwest part of the basin.

\subsection{Decadal variability}

To understand the precipitation variability on a decade basis, decadal apportionment disorder index (DADI) was calculated at the stations located in Songhua River basin. Figure 6(a) depicts the mean value of DADI, used to understand the spatial variability over different stations and decades, experiencing higher precipitation variability. Mean DADI with long-term mean was also calculated to understand the variability of precipitation as shown in figure $6(\mathrm{~b})$. The values above from the long-term mean showed a higher precipitation 

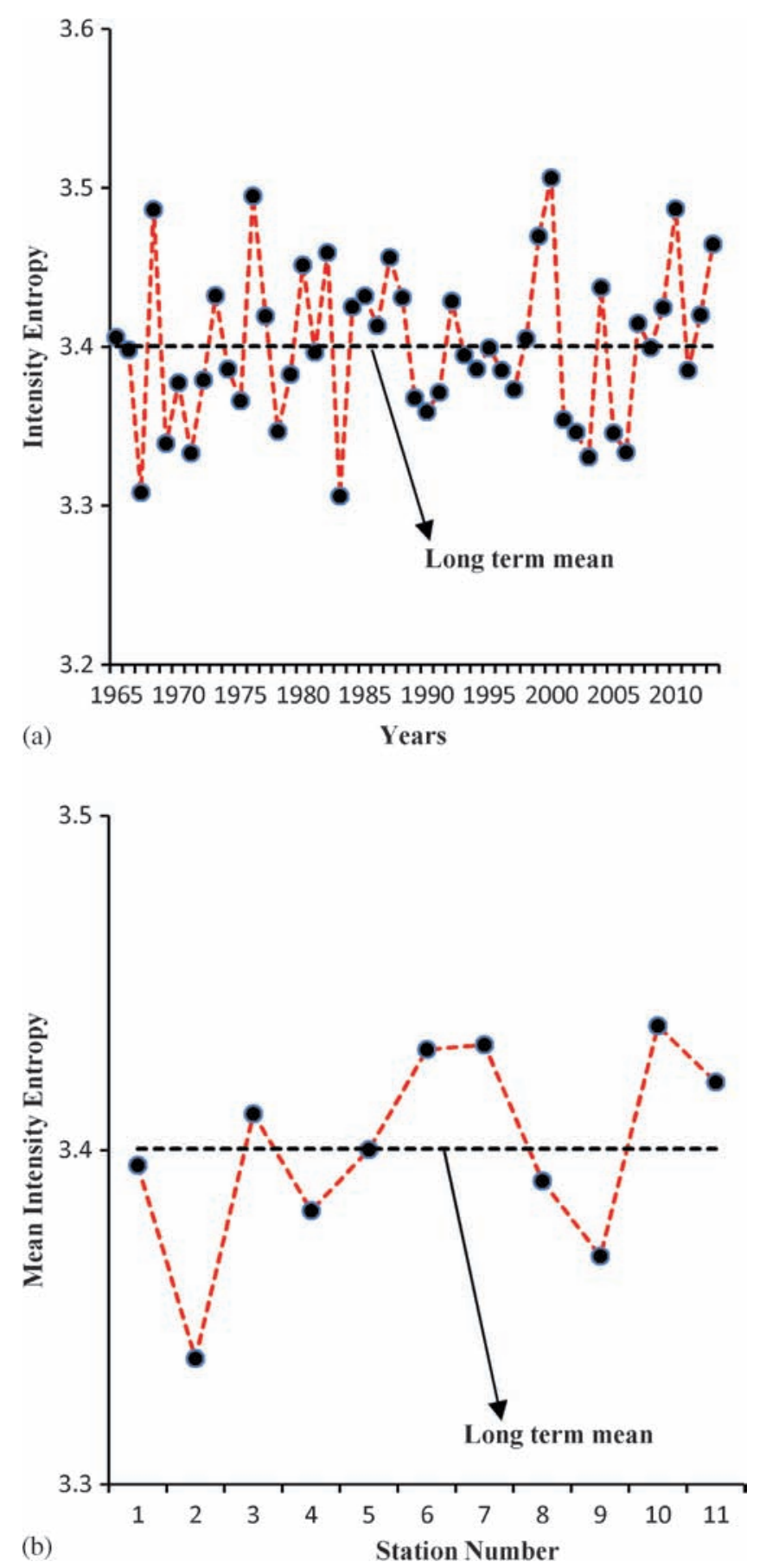

Figure 5. (a) Mean intensity entropy of different years over various precipitation stations. (b) Station-wise mean intensity entropy of precipitation.

variability and the values below the long-term mean showed a lesser variability of precipitation over decades and at stations. It can be seen in figure $6(\mathrm{~b})$, the highest precipitation variability with mean DADI value (0.089) at Bayan station (2) as compared to other stations. The lowest precipitation variability was observed at Yilan station (3) during all decades with a mean DADI value of 0.017. The Bayan and Yilan stations are located
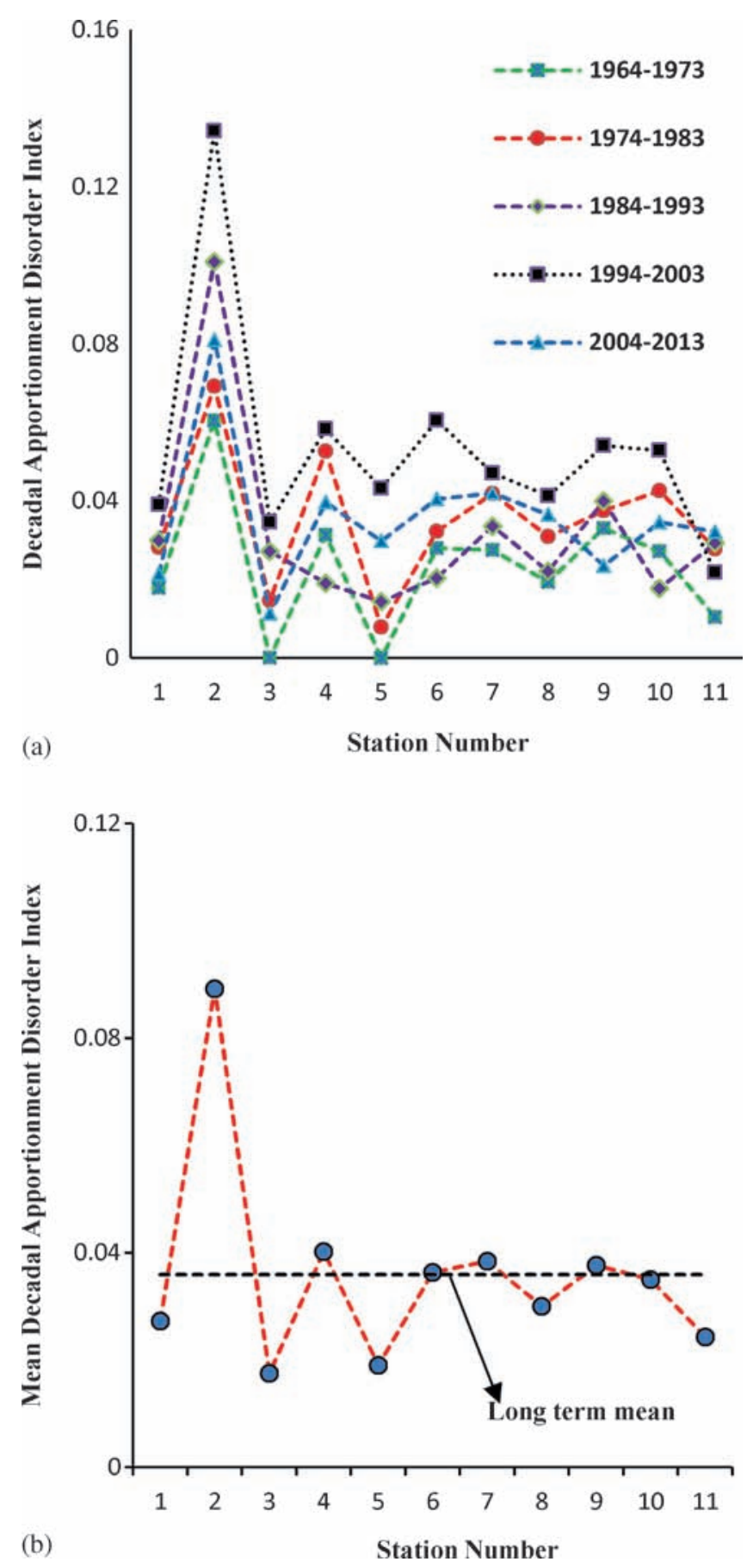

Figure 6. (a) Mean decadal apportionment disorder index of precipitation over different decades. (b) Mean decadal apportionment disorder index of each precipitation stationwise.

at north and east parts of the study basin, respectively. Additionally, the comparison analysis of two decades (1964-1973 and 1994-2003) showed that the decade 1994-2003 experienced a higher precipitation variability (DADI of 0.053 ) in comparison with the decade 1964-1973 (DADI of 0.023 ). Figure $6(\mathrm{a})$ depicts that the variability is continuously increasing from the decade 1964-1973 to 1994-2003. These results are in agreement 
with those of Ding et al. (2008) who observed that an increasing trend in precipitation variability was observed from 1960's to 1980's, in north China. During the last decade (2004-2013), however, a slight decline in precipitation variability was observed, as analysed in this study. Similarly, by plotting mean DADI values with threshold values in figure 6(b), it was noticed that the Bayan station experienced a higher variability during all decades in comparison with all the other stations located in the study basin. Moreover, less variability was found at Tonghe station (mean DADI value of 0.038 ) which is very close to threshold DADI value (0.036).

\subsection{Trend of precipitation variability}

\subsubsection{Mann-Kendall and Spearman's Rho statistics}

Figure 7 depicts the variability in the trend of precipitation at each station located within Songhua River basin. Figure 7 depicted that out of the 11 studied, only Shangzhi station (10) showed a significantly positive trend with value of $Z_{S}$ (1.9). Our results are in line with Song et al. (2015) who reported that only 4 precipitation stations, out of 39 showed a significant positive trend in Songhua River basin. The Spearman's Rho and MannKendall test showed some upward positive trends at some stations; however, overall no significant trend was found throughout the stations located within the study area. The stations such as Downtown (1),

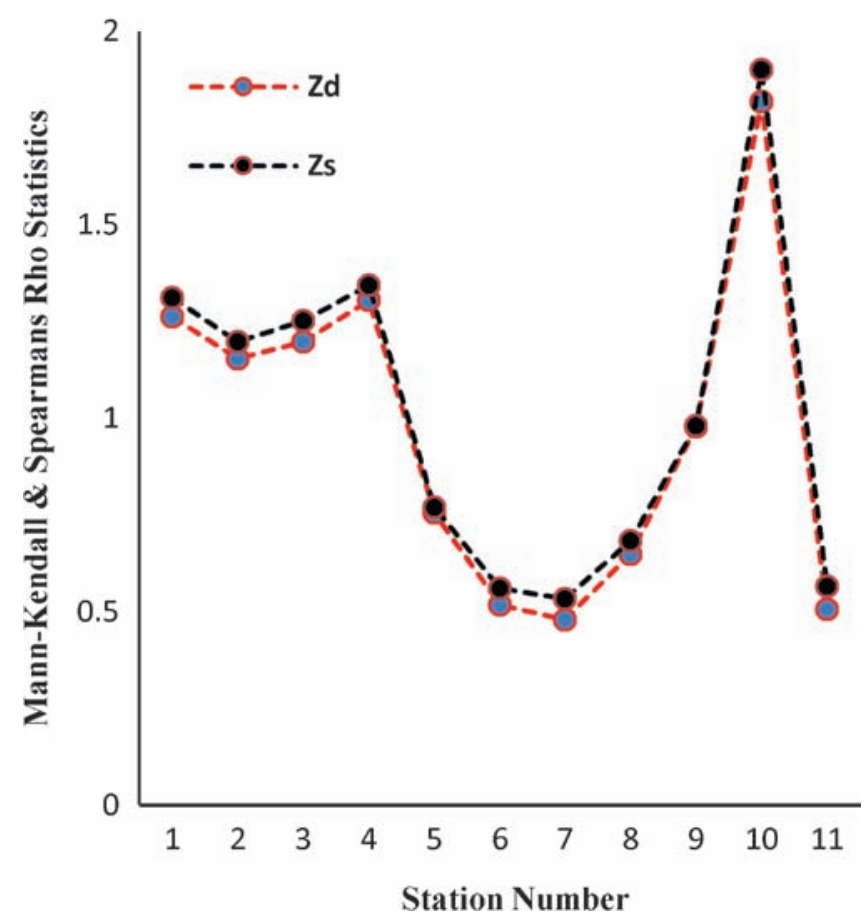

Figure 7. Mann-Kendall and Spearman's Rho statistics of precipitation time series.
Bayan (2), Yilan (3) and Shuangcheng (4) showed upward trends. These precipitation stations are located on the northwest to northeast of the study basin. It means that the northeast to the northwest part of Songhua River basin will undergo longterm precipitation variability with upward trends in future.

\section{Conclusion}

The study presented the variability in precipitation on monthly, seasonally, annually, decadal and number of rainy days in Songhua River basin, China. The results suggest that the maximum variability in monthly precipitation was found in July (summer), April (spring), February (winter) and very slight variations between months of fall season (September and October). The seasonal precipitation analysis reveals that the highest variability was found during winter and the lowest during the fall season which indicates that this study area largely depends upon the westerlies circulation precipitation pattern. The variability in precipitation on an annual basis is very low as compared to monthly and seasonal variations. The precipitation variability on decade basis, shows an increasing trend from $1964-1973$ to $1994-2003$. On the basis of rainy day analysis, it reveals that the maximum number of rainy days occurred during 1978. Moreover, the trend of number of rainy days in a month is consistent. Generally, the precipitation variability on temporal (annual) and spatial basis is decreasing from north to south of Songhua River basin. Long-term persistence has been observed in most of the precipitation stations.

The Songhua River basin experiences a high variation in precipitation which is increasing from north to south due to the topography and monsoon. The high variability in precipitation leads to scarcity of water and a threat to the development of agriculture in the region as Heilongjiang is a key agriculture region for agriculture production in China. All these factors advocate that suitable strategies are needed to meet the agricultural water needs and the protection of ecosystem in the study area. For further research, it is recommended that the climatic variables such as temperature, evaporation and variation in the wind speed should be analysed because these climatic variables can affect the precipitation trends and variation in precipitation can affect the changes in climate.

\section{Acknowledgements}

This study was supported by the National Natural Science Foundation of China (No. 41071053, No. 51479032), Sub-Task of National Science and 
Technology Support Program for Rural Development in the 12th Five-Year Plan of China (No. 2013BAD20B04-S3), Specialized Research Fund for the Public Welfare Industry of the Ministry of Water Resources (No. 201301096), Specialized Research Fund for Innovative Talents of Harbin (Excellent Academic Leader) (No. 2013RFXXJ001), Science and Technology Research Program of Education Department of Heilongjiang Province (No. 12531012), Science and Technology Program of Water Conservancy of Heilongjiang Province (No. 201319) and the Northeast Agricultural University Innovation Foundation For Postgraduate (No.yjscx14069).

\section{References}

Azmat M 2015 Water Resources Availability and Hydropower Production under Current and Future Climate Scenarios: The Case of Jhelum River Basin, Pakistan; Ph.D dissertation, Politecnico di Torino, Italy.

Azmat M, Laio F and Poggi D 2015 Estimation of water resources availability and mini-hydro productivity in high-altitude scarcely-gauged watershed; Water Resour. Manag. 29 5037-5054.

Azmat M, Choi M, Kim T-W and Liaqat U W 2016 Hydrological modeling to simulate streamflow under changing climate in a scarcely gauged cryosphere catchment; Environ. Earth Sci. 75(3) 1-16.

Beniston M and Stephenson D B 2004 Extreme climatic events and their evolution under changing climatic conditions; Global Planet. Change 44(1) 1-9.

Cannarozzo M, Noto L V and Viola F 2006 Spatial distribution of rainfall trends in Sicily (1921-2000); Phys. Chem. Earth 31(18) 1201-1211.

Ding Y, Wang Z and Sun Y 2008 Inter-decadal variation of the summer precipitation in east China and its association with decreasing Asian summer monsoon. Part I: Observed evidences; Int. J. Climatol. 28(9) 1139-1162.

Fu G B, Yu J J, Yu X B, Ouyang R L, Zhang Y C, Wang P, Liu W B and Min L L 2013 Temporal variation of extreme rainfall events in China, 1961-2009; J. Hydrol. 487 48-59.

Guo L, Ma K M and Zhang Y 2009 Denitrification potential of different land use types in Jiansanjiang District; J. Agro-Environ. Sci. 28(5) 941-945 (in Chinese).

Haigh M J 2004 Sustainable management of head water resources: The Nairobi head water declaration (2002) and beyond; Asian J. Water Environ. Pollut. 1(1) 17-28.

IPCC (intergovernmental panel on climate change) 2013 Summary for Policymakers; In: Climate Change 2013: The Physical Science Basis, Contribution of Working Group I to the Fifth Assessment Report of the Intergovernmental Panel on Climate Change Cambridge University Press, Cambridge, United Kingdom and New York, NY, USA.
Kawachi T, Maruyama T and Singh V P 2001 Rainfall entropy for delineation of water resources zones in Japan; J. Hydrol. 246(1) 36-44.

Kendall M G 1975 Rank Correlation Methods; Griffin \& Co, London. ISBN 0-85264-199-0.

Lake D E, Richman J S, Griffin M P and Moorman J R 2002 Sample entropy analysis of neonatal heart rate variability; Am. J. Physiol.-Reg. I 283 789-797.

Lehmann E L 1975 Nonparametric Statistical Methods Based on Ranks; Holden-Day, San Francisco.

Li F P, Zhang G X and Xu Y J 2014 Spatiotemporal variability of climate and stream flow in the Songhua River basin, northeast China; J. Hydrol. 514 53-64.

Liang L Q, Li L J and Liu Q 2011 Precipitation variability in northeast China from 1961 to 2008; J. Hydrol. 404(1-2) $67-76$.

Liu M, Xu X, Sun A Y, Wang K, Liu W and Zhang X 2014 Is southwestern China experiencing more frequent precipitation extremes?; Environ. Res. Lett. 9(6) 064002.

Mann H B 1945 Nonparametric tests against trend; Econometrica 13 245-259.

Maruyama T and Kawachi T 1998 Evaluation of rainfall characteristics using entropy; J. Rainwater Catchment Systems 4(1) 7-10.

Mann M E and Park J 1999 Oscillatory spatiotemporal signal detection in climate studies; Adv. Geophys. $\mathbf{4 1 0}$ $1-131$.

Oguntunde P G, Friesen J, Van de Giesen N and Savenije H H 2006 Hydro climatology of the Volta River basin in west Africa: Trends and variability from 1901 to 2002; Phys. Chem. Earth 31 1180-1188.

Richman J S and Moorman J R 2000 Physiological timeseries analysis using approximate entropy and sample entropy; Am. J. Physiol.-Heart C. 278 H2039-H2049.

Shannon C E 1948 A mathematical theory of communication; Bell Syst. Tech. J. 27 379-423.

Singh V P 1997 The use of entropy in hydrology and water resources; Hydrol. Process. 11 587-626.

Singh V P and Fiorentino M 1992 Entropy and Energy Dissipation in Water resources; Kluwer Academic Publishers, Dordrechth, pp. 21-61.

Sneyers R 1990 On the Statistical Analysis of Series of Observations; World Meteorological Organization, Technical Note No. 143 WMO No. 415.

Song X, Song S, Sun W, Mu X, Wang S, Li J and Li Y 2015 Recent changes in extreme precipitation and drought over the Songhua River basin, China, during 1960-2013; Atmos. Res. 157 137-152.

Yang T, Shao Q, Hao Z C, Chen X, Zhang Z, Xu C Y and Sun L 2010 Regional frequency analysis and spatio temporal pattern characterization of rainfall extremes in the Pearl River basin, China; J. Hydrol. 380(3) 386-405.

Zhang M, He J, Wang B, Wang S, Li S, Liu W and Ma X 2013 Extreme drought changes in southwest China from 1960 to 2009; J. Geogr. Sci. 23(1) 3-16.

Zhang Q, Singh V P, Sun P, Chen X, Zhang Z and Li J 2011 Precipitation and Stream flow changes in China: Changing patterns, causes and implications; J. Hydrol. 410 204216. 